\title{
La formación de lectores de literatura capaces de alcanzar el efecto estético por medio de la intertextualidad ${ }^{*}$
}

FORMING LITERATURE READERS CAPABLE OF ACHIEVING AESTHETIC EFFECT THROUGH

INTERTEXTUALITY

A FORMAÇÃO DE LEITORES DE LITERATURA CAPAZES DE ATINGIR O EFEITO ESTÉTICO POR MÉDIO DA INTERTEXTUALIDAD

Carlos Andrés Herrera Pérez* / rottingandres@yahoo.com

Alirio Sneider Saavedra Rey*** sneider201@hotmail.com

\section{Resumen}

Desde una comprensión de la lectura literaria como experiencia estética, la investigación homónima que se resume en este artículo, plantea una propuesta didáctica basada en la teoría de la recepción y la intertextualidad, con el propósito de formar lectores capaces de alcanzar el efecto estético. La investigación-acción, desarrollada en dos ciclos en dos colegios, configura un proceso de lectura que involucra la experiencia vital, el contexto e intertextos del cine y la minificción, posibilitando diversos horizontes de sentido y consolidando una formación lectora significativa en el estudiante.

\section{Summary}

Based on the comprehension of literary reading as an aesthetic experience, the homonymous research that is summarized in this article presents a didactic proposal based on the reception theory and the intertextuality in order to form readers able to produce an aesthetic response. Developed in two cycles in two schools, the action research establishes a reading process that involves life experience, context and intertexts from cinema and minifiction, making possible several horizons of expectations and consolidating a significant reading education.

\section{Resumo}

Partindo da compreensão da leitura literária como uma experiência estética, a pesquisa homónima apresentada neste artigo propõe uma aproximação didática baseada na teoria da recepção e a intertextualidade no propósito de formar leitores com capacidade de atingir o efeito estético. A investigação-ação desenvolvida nos dois ciclos configura um processo de leitura que inclui a experiência vital, o contexto e intertextos do cinema e a mini-ficção possibilitando diversos horizontes de sentido e consolidando uma formação leitora significativa no estudante.

* Investigación perteneciente a la Facultad de Humanidades de la Universidad Pedagógica Nacional y desarrollada en las instituciones educativas del Liceo Católico y la República de Panamá (IED).

** Licenciado en Humanidades, Español y Lenguas extranjeras de la Universidad Pedagógica Nacional. Trabaja en la Universidad de La Salle.

*** Magíster en Educación y Licenciado en Humanidades, Español y Lenguas extranjeras de la Universidad Pedagógica Nacional. Profesor de la Universidad Pedagógica Nacional y del Liceo de Cervantes.

Fecha de recepción: 14 de septiembre de 2012 / Fecha de aprobación: 18 de octubre de 2012 


\section{Introducción}

El objetivo de formar lectores de literatura capaces de alcanzar el efecto estético suscita interrogantes de tipo epistemológico, pedagógico y metodológico, pues supone que el contexto donde se sitúa el proyecto ha consolidado "lectores ocupados" en la recolección de datos textuales y contextuales, que por sí mismos dan cuenta de la "importancia" de las obras, y no "desocupados lectores" que, a semejanza de lo propuesto en el célebre prólogo del Quijote, se atrevan a explorar los horizontes de sentido que propone un texto literario.

En este sentido, la investigación de este artículo cuestiona las prácticas de lectura desarrolladas en las aulas de clase que no entienden la intencionalidad estética de lo literario, de acuerdo con las discusiones teóricas sobre los múltiples procesos formativos que activa su lectura. Por ello, aborda los siguientes cuestionamientos pedagógicos: ¿Cuáles son los propósitos de la enseñanza de la lectura?, ¿cuáles son sus rasgos específicos cuando se lee esa modalidad particular de lo literario? En el sistema educativo colombiano, ¿se enseña a leer literatura para construir sentido y disfrutar los textos, es decir, para explorar sus posibilidades discursivas?, o ¿se limita a reproducciones temáticas predeterminadas?

Si bien los Estándares curriculares de Lenguaje, lengua y otros sistemas simbólicos (2003) y los Lineamientos curriculares de Lengua Castellana (1998) proponen "el placer por la lectura" y el "goce literario" como aspectos fundamentales para la consolidación lectora, esta investigación demuestra que no se ha constituido una sensibilidad que contribuya a "convertir el goce literario en objeto de enseñanza para promover el desarrollo de competencias relacionadas con lo estético, lo emocional, lo cultural, lo cognoscitivo y lo pragmático" (MEN, 2003, p. 24) . Al tiempo, esta situación suscita el analfabetismo funcional o "iletrismo" (Ferreiro, 2001) de tantos estudiantes de bachillerato, y otras problemáticas culturales, como su pobre desempeño académico o los bajos índices de consumo de libros en el país (Venegas, 2001), pues no se logran conformar comunidades que trasciendan las aulas en la comprensión de la lectura como práctica social (Lerner, 2001).

Por esta razón, se propone la lectura de obras literarias como estrategia para potenciar el nivel de comprensión e interpretación de cualquier tipo de texto (incluso, no lingüístico), dada la amplitud de sus posibilidades discursivas, mediante diversos conocimientos y experiencias brindadas por la intertextualidad del cine y la minificción. Así, se aborda

Rollos nacionales / La formación de lectores de literatura capaces de alcanzar el efecto estético por medio de la intertextualidad / Carlos Andrés Herrera Pérez / Alirio Sneider Saavedra Rey 
una obra perteneciente a un contexto sociocultural particular (en lo que tantas veces se agotan las clases de literatura), que se configura por elementos y reglas de funcionamiento interno; $y$ se revisa su especificidad literaria (muchas veces precisada pero difícilmente partícipe de la praxis lectora) que se actualiza con cada lector de acuerdo con su bagaje cultural y experiencial, generándole un efecto estético único e irrepetible, otra experiencia, en la que no se agotan sus múltiples sentidos.

\section{Marco teórico}

\section{Hacia una didáctica de la literatura de y para} la vida

De los textos construidos por signos lingüísticos la obra literaria es el único desarrollado con fines intencionalmente estéticos desde su esencia polisémica y su constante indagación por las posibilidades de la lengua y el lenguaje; lo hace hasta convertirse, como afirman Ricoeur (1995) o Bruner (2004), en una indagación por la condición humana. El texto literario desarrolla las posibilidades discursivas del lenguaje estableciendo nexos ineludibles con el mundo de la vida (Colomer, 1995). Además, tiene una clara intención de tocar al lector en su "ser profundo", como acto de reconocimiento de su esencia humana (Fortich, 2008). No se trata de un texto más, que sólo se distingue teóricamente dentro de las tipologías discursivas, sino que su valor concierne a la experiencia vital de quienes interactúan en sus producciones de sentido.

Nadie puede negar el valor de la literatura como arte del ser humano para el ser humano, ni el de la lectura como fuente enriquecedora que expande y profundiza la personalidad de los jóvenes, cuando se la reelabora y se la hace propia [...] El que lee participa cognitiva, emotiva e imaginativamente del discurso de la humanidad (Reyzábal y Tenorio, 1994, p. 38).

Así, la enseñanza de la literatura traspasa las fronteras de lo lingüístico para ingresar a los terrenos de la experiencia vital compuesta de sentidos que se generan, desarrollan y caducan en la dinámica de la existencia histórica del individuo, y que a su vez están reflejados en la obra de arte como testimonio de una época y una experiencia específicas (las de su creador), susceptibles de ser cargadas con nuevos sentidos y posibilidades para encarar la realidad. "La literatura, más allá de su función lingüístico-didáctica, es un "escenario simbólico del mundo" que posibilita una versión de lo real" (Ferrer, 2002, p. 16). Esto evidencia esa relación entre la "lectura de la palabra" y la "lectura del mundo" que enuncia Freire (2005), que es inseparable debido a que ambas posibilitan la incursión en el mundo, su redescubrimiento, en un vínculo dinámico entre lenguaje y realidad.

En consecuencia, la literatura debe ser enseñada como medio y elemento, de la libertad, que le permite al hombre la posibilidad de acercarse a sí mismo desde el otro, ya sea éste autor, narrador o personaje, siempre sujeto susceptible de que el lector se identifique con él, con su vida o con su situación en el mundo. En este panorama, es el profesor de literatura el encargado de constituirse en mediador entre los sentidos potenciales de la obra literaria y del arte en general, y los estudiantes, sus interpretaciones y percepciones.

Este tinglado de horizontes de sentido será precisamente el que genere el efecto estético como contingencia de la comprensión e interpretación textual, así como su afectación en el lector, pues al construir sentido desde la alteridad: "la literatura ofrece la posibilidad de formularnos a nosotros mismos por medio de la formulación de lo no formulado" (Iser, 1987, p. 250), explorando y proponiendo desde la subjetividad, desde lo que cada uno es; una versión de los hechos en la que uno mismo es reformulado, expuesto, transformado.

Con este propósito en mente, es indispensable el conocimiento del contexto de la obra, de su creador y del lector, para crear puentes entre aspectos ideológicos, cognitivos, sociales y estéticos que a su vez permitan la socialización de la experiencia lectora y el análisis de la obra dentro del aula. Tal contexto de enseñanza permite reconocer las características de sus participantes, sus intereses, desarrollos plausibles y, en consecuencia, los textos a abordar, en cuyo trabajo se consideran pertinentes los niveles de lectura propuestos por Ferrer (2002): descriptivo, que reconoce lo estético como hecho histórico referido a la lectura de lo propuesto, por lo cual busca fragmentar el discurso en unidades comunicativas básicas; pragmático, que relaciona dichas unidades en la constitución de la obra artística; e ideológico, que trasciende a la formulación 
de hipótesis de sentido en relación con el mundo real a partir de la propuesta estética.

El hecho de transcurrir durante el proceso de lectura por estos tres niveles es lo que permite conocer la manera en que se relaciona el discurso literario con el lector, cómo lo afecta, cómo determina su visión de mundo, etc., pues está desarrollando una nueva experiencia en el sentido propuesto por Larrosa (1998), como esa relación íntima entre el texto y la subjetividad, que sobrepasa el simple consumo de una obra o el desciframiento de un código. En su reverso, también permite vislumbrar cómo influye el lector en el texto, puesto que la obra literaria es dinámica y trascendente, no se estanca en la historia; susceptible de múltiples procesos de resignificación al "interactuar" con sujetos de lugares y épocas distintas.

\section{La lectura como experiencia estética}

Iser (1987), en El acto de leer. Teoría del efecto estético, enfatiza acerca del potencial de efectos de los textos literarios, los cuales sólo pueden ser actualizados mediante la "reelaboración" que hace el lector en su conciencia. Por esta razón, su propuesta no remite a una teoría de la recepción, basada en los juicios históricos del lector, sino a una Teoría del efecto estético anclada en la obra, constituida por el "polo artístico" (el texto creado por el autor) y el "polo estético" (la concreción del texto realizada por el lector durante su lectura), de lo que se deriva que sólo cuando texto y lector convergen significativamente se constituye tanto la lectura como la obra.

Impulsado por el texto, el lector crea una nueva situación, única e irrepetible, que es su propia percepción, su propia experiencia (un mundo no formulado) de la obra literaria; es esto lo que se define como efecto estético. Por supuesto, este proceso supone que su interpretación no dilucide el sentido sino los potenciales de sentido (de acuerdo con el lector concreto, con su experiencia específica), los cuales dan cuenta del carácter estético de la obra sin reducir sus posibilidades semánticas y discursivas.

Esta construcción de sentido, más allá del desciframiento de un código, constituye la experiencia de lectura como un acto de formación y transformación para quien lee, a través de la transgresión de dicho código (Larrosa, 1998). Se trata, en palabras de Borges (2001), de reconocer los libros como "objetos físicos de símbolos muertos", hasta que llega el lector adecuado para hacerlos surgir a la vida, para forjar una "resurrección del mundo". De nuevo con Iser (1987), esto implica que el lector experimente el texto y el sentido que construye como algo real, como "acontecimiento", más aún cuando se le presenta como algo no experimentado, lo cual no sólo debe ser interpretado sino que logra su éxito en la medida en que formula en el lector algo que hasta ese momento parecía sustraerse de su propia conciencia.

\section{Fundamentos para una fenomenología de la} lectura

Iser (1987), supera la dicotomía sujeto-objeto y precisa el proceso entre el "punto de visión móvil" y la "síntesis", mediante el cual el lector construye el texto como correlato de su conciencia, pues éste no puede considerarse objeto de percepción debido a que sólo se presenta como un todo cerrado al final de la lectura. Activando el concierto de "correlatos intencionales de la frase", el lector inicia un proceso dialéctico de "protención" y "retención", a través del cual se organiza el texto, pues, como cada correlato de la frase apunta a lo que sigue, siempre se organiza la secuencia de la frase y ésta, a su vez, abre un horizonte al interior del texto, crea una expectativa que puede ser cumplida (visión saturada) o mantenida sin resolución (representación vacía). Esta tensión esquematiza una primera visión de la actividad sintética de la lectura a partir de la ordenación de múltiples "horizontes de lectura" interiores $y$, por tanto, de la manera en que el lector va dando forma al material textual en cuestión.

En consecuencia, el "punto de visión móvil" es capaz de desarrollar una red de relaciones que permite mantener dispuesta la totalidad del texto en distintos instantes de la lectura (a través de la tensión de recuerdos y expectativas sobre el mismo, es decir, su síntesis). Esto proporciona una base sobre la cual el lector puede tomar decisiones selectivas durante su lectura, las cuales, lógicamente, no son idénticas a las de otros lectores, pero sí comprensibles en tanto surgidas de la misma red de relaciones, lo cual fundamenta el propósito investigativo aquí propuesto, de fomentar el proceso de cada lectura particular de los estudiantes para propiciar el efecto estético. Por ello, se retoman estos conceptos propuestos por Iser (1987): 
a. La figura como producción de lo no-manifestado lingüísticamente por parte del lector a partir de los signos del texto. Se destacan dos tipos fundamentales: uno, referido a los acontecimientos, cuya necesidad selectiva se ha minimizado. Sobre este se construye una segunda figura que termina la formación de la anterior y que se establece en el nivel del sentido, la cual resulta más arbitraria de acuerdo con las "decisiones selectivas" del lector. La pertinencia y justificación de estas figuras se plantea en términos de su consistencia, referida a los argumentos para su planteamiento.

b. Las síntesis pasivas refieren a las elaboraciones del lector durante su proceso de lectura, dado que su constitución (pre-predicativa, no de juicios) se produce debajo de su umbral de conciencia. Su manifestación central son las "imágenes de la representación" que, en oposición a la percepción inmediata del objeto de las "imágenes de la percepción", se dan a partir de lo no-dado que se ofrece al lector.

c. Esta configuración de las representaciones abarca la relación permanente entre el tema, la significatividad y la interpretación. El primero se refiere a la atención que el lector, limitado por el repertorio del texto, toma con respecto a algo específico de la obra. La significatividad se configura en relación con la representación en cuanto llena los vacíos dejados por el tema, haciendo evidente lo que el texto calla. Esto explicita la modalidad central del texto de ficción: la "negatividad de su repertorio", la cual potencia en su silencio los diversos "horizontes de sentido" que posibilitan la interpretación.

d. El sentido es la referencia determinada por los aspectos del texto (contexto interno) que se debe constituir en la lectura. El significado traduce este sentido a otro sistema de referencias de su mundo (el código sociocultural, las valoraciones individuales, etc.), interpretándolo a través de los datos de dicho sistema. Así, la lectura del texto se desarrolla a través de un proceso de comprensión de su sentido que trasciende a otros sistemas de referencia como interpretación.

e. Desde la perspectiva fenomenológica, dicha constitución del sentido y del sujeto lector resultan dos operaciones bilaterales, reforzadas mutuamente por el texto. En ellas se suspende la experiencia histórica del sujeto real, al encarar como acontecimiento algo extraño, lo cual lo hace partícipe de una irrealidad, mientras elabora el texto como correlato de su conciencia.

\section{Intertextualidad mediante el cine y la minificción para la formación lectora}

Debido a la amplitud de la "intertextualidad", que aborda desde alusiones o citas que transitan de un texto a otro, conexiones entre obras, influencia entre autores, aspectos contextuales, hasta relaciones con textos no lingüísticos, se ha optado por la "intertextualidad literaria", definida como la "relación que un texto literario mantiene desde su interior con otros textos, sean éstos literarios o no" (Martínez, 2001, p. 45).

Esta concepción, basada en consideraciones clásicas como la de Kristeva: "todo texto se construye como un mosaico de citas, todo texto es absorción y transformación de otro texto", o la de Barthes: "todo texto es un intertexto [...] todo texto es un tejido nuevo de citas anteriores" (Citado por Martínez, 2001, p. 74), denota su importancia en el momento de leer cualquier texto (en especial, una obra literaria), pues a través de las relaciones que se pueden establecer entre el texto inicial (subtexto) y su aparición como intertexto en otros (por mencionar sólo un mecanismo), se enriquece el espectro de posibilidades de lectura de las obras, sus horizontes de sentido, y por tanto se potencian los niveles de comprensión e interpretación textuales.

Así pues, la intertextualidad permite ampliar las posibilidades de configuración del efecto estético en la lectura, además de contribuir a la formación de un lector competente para lecturas posteriores, con cierto bagaje cultural y una disposición que le permita comprometerse cada vez más con el proceso lector $y$, por tanto, desempeñarse mejor lectura tras lectura.

Con el propósito de crear esos canales de comunicación entre los textos para dilatar los horizontes de sentido y profundizar las interpretaciones textuales, se propone el lenguaje cinematográfico, la minificción y "extratextos" históricos e informativos. Estos últimos se justifican por sí mismos, pues permiten configurar el contexto, informando sobre los aspectos espaciotemporales en que se crearon las obras leídas. Por su parte, los "intertextos" propuestos evidencian un modo 


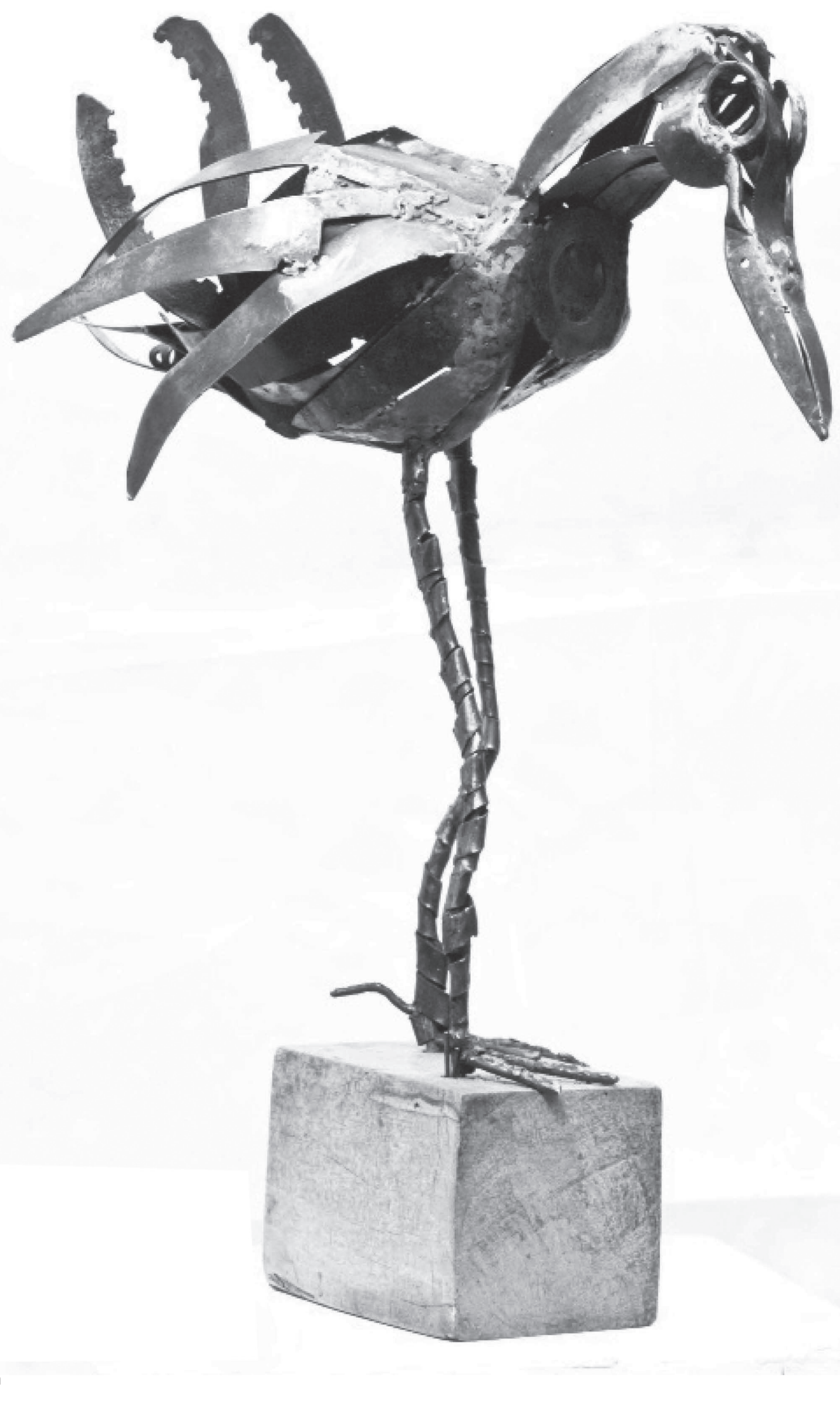

Artista: Felipe Ruiz

Tecnica: Escultura en metal

Año: 2010 
de leer las narraciones que contribuye a la construcción de sentido de cualquier tipo de texto, así como a la sensibilización artística que amerita cualquier propuesta cuyo objetivo es alcanzar el efecto estético, más aún en el mundo actual, configurado por la brevedad, la interactividad, la virtualidad y el predominio de la imagen.

Debido a su brevedad y contundencia en la evocación de imágenes de representación en la conciencia del lector, a los juegos intertextuales que proponen y al énfasis en la indagación del mundo que posibilita su configuración, la minificción y el cine, además de evidenciar nuevas formas de leer y escribir el mundo contemporáneo, en tanto género literario posmoderno (Zabala, 2005), constituyen un puente entre los jóvenes, el complejo mundo literario y la lectura. Es más, la reciprocidad, dada de manera histórica, entre las formas de leer el cine y la literatura (Gimferrer, 2000), permite el acceso a diversos saberes de modo interdisciplinar (Pujals y Romea, 2001), ampliando los horizontes de sentido de los textos para lograr el efecto estético.

\section{Metodología}

De acuerdo con la definición de Mckernan (2001), la investigación-acción plantea el papel protagónico de los involucrados en el proceso educativo (profesores, investigadores y estudiantes de grado undécimo de dos instituciones educativas) en la reflexión rigurosa y sistemática de alguna problemática localizada (la lectura de textos literarios), a partir de la cual se propone una hipótesis para generar un cambio (el alcance del efecto estético en la interacción lectortexto) que contribuya al mejoramiento del proceso educativo (la formación en lenguaje y literatura).

Este proceso se desarrolla en dos ciclos de acción: uno de diagnóstico y exploración, y otro de aplicación de una propuesta didáctica de lectura literaria a través de la intertextualidad. Este último se divide en tres sub-ciclos, en los cuales se redefine el problema y las necesidades (carencia de material simbólico para la interpretación y goce de la obra literaria), se crean nuevas hipótesis, se pone en práctica la propuesta didáctica y, finalmente, se evalúa la acción y se reflexiona para tomar decisiones de acuerdo con su pertinencia.

\section{Resultados}

\section{Ciclo de diagnóstico y exploración}

Durante el diagnóstico desarrollado, en el grado undécimo de dos instituciones educativas, los estudiantes afirmaron frecuentemente frases como: "lo que pasa en esos libros es muy 'ficti'; lo que nos gusta es lo que tiene que ver con nuestra realidad como jóvenes". Esto evidenció una falta de relación del contenido de las obras trabajadas con sus vidas, limitándose al reconocimiento de aspectos textuales. Así mismo, dentro de sus intereses mencionaron el amor y la violencia y la lectura de biografías de famosos, pues, según ellos, estos temas sí tienen que ver con su cotidianidad.

Sobre la didáctica empleada por los profesores, los grupos afirmaron haber trabajado la mayoría de las sesiones en grupo con el apoyo de guías de lectura y talleres, cuyo análisis evidenció un abordaje tradicional de los textos narrativos que no trascendía lo anecdótico y la instrumentalización de la literatura, pues se trabajaban temas gramaticales y ortográficos, así como la comprensión lectora para el examen de Estado.

De hecho, en observaciones y entrevistas informales realizadas a los docentes, se hizo evidente la apatía de los estudiantes por la lectura y su bajo nivel de comprensión. Expresiones como: "no están acostumbrados a leer" o "no son conscientes de la importancia de saber leer para el ICFES", evidenciaron un distanciamiento del proceso de sus estudiantes, atribuyéndoles la responsabilidad total del problema o incluyendo a un tercero -los medios, la escuela, etc.- como responsable de la distancia entre los estudiantes y la lectura.

\section{Ciclo de aplicación}

En el primer ciclo se desarrollaron actividades que permitieron el diseño de la guía didáctica constituida por tres módulos, a partir de los cuales se desarrollaron tres sesiones con la siguiente secuencia: proyección de la película, debate, conversatorio con el profesor y elaboración de un escrito por parte de los estudiantes sobre su experiencia lectora. Para finalizar cada módulo, se desarrolló la sesión 3 a partir de la lectura de textos literarios, su interpretación, la relación con la película y con los módulos anteriores, con el fin de elaborar un escrito final sobre estos aspectos y las experiencias tratadas. 


\section{Módulo 1. Violencia y literatura}

Para identificar las categorías recurrentes en la interacción de los estudiantes con el documental, se hizo una observación de sus actitudes desde el momento en el que fue propuesto como material de trabajo. Ellos estuvieron interesados debido a que refleja los conflictos de los jóvenes colombianos. Durante la proyección, sus actitudes hicieron evidente las síntesis pasivas que estaban elaborando, pues de manera inconsciente estaban relacionando el contenido de La Sierra, con lo visto en otros textos y con conceptos de diferentes tipos; sin embargo, una vez visto el documental, los vacíos conceptuales de los estudiantes para interpretar el texto se hicieron evidentes en la sesión de preguntas.

Las imágenes de percepción tuvieron más fuerza que las de representación en su lectura de La Sierra, pues los textos que produjeron el contenido explícito del documental fueron el tema principal de sus opiniones. Esto es evidente en los textos que escribieron: "El manco, quien perdió su brazo el 7 de Diciembre en una balacera", o "la imagen que me impactó al ver el documental La Sierra, fue la del instante en que muestran una señora en la mitad de la calle muerta, botada en el piso y, al parecer, a causa de balas". Este tipo de imágenes obedece a una lectura exclusiva del sentido del texto, que no accede al significado.

Además, otras apreciaciones, vinculadas con juicios morales y afectivos, interfirieron en la interacción de los estudiantes con el documental, predeterminando los horizontes de sentido. Un ejemplo de esto se encuentra en la siguiente opinión: "es duro ver que así estamos hoy en día, los muchachos en las drogas y las mujeres adolescentes jóvenes en la prostitución; sería bueno que este mundo cambiara y que todos fuéramos personas de bien".

Se observó una diferencia en la reproducción de imágenes con respecto al componente literario de este módulo, La duda de Gaitán Durán, pues refirió a imágenes de representación, especialmente a partir de las expresiones "vuelto pura mente" que hace alusión a un hombre muerto y de la descripción de cómo una "bala le tumbó los dientes al otro y se le fue hasta el cráneo", pues en ambas los estudiantes lograron hacer una representación más allá de lo perceptual que ofrece el texto. Un estudiante mencionó "el estado putrefacto de alguien al que sólo le queda la mente", y otro: "la mente es vacía, en el cuento es lo único que queda del hombre". Así mismo, las alusiones al sol ardiente y las sombras dejaron muy claro el contexto, lo cual demuestra una recurrencia en la activación de imágenes de representación.

Finalmente, la estructura del lenguaje que propone la obra, activa horizontes de sentido cambiantes, generando expectativas en el lector para elaborar una comprensión e interpretación del mismo. Los estudiantes mencionaron la dificultad de entender "el hilo" del cuento, porque comienza hablando de "lo que hace un hombre, luego se descubre que es como un militar, luego que es izquierdista, pues eso parece; entonces parece que va a matar a alguien pero no se sabe el porqué ni a quién, y sólo al final se sabe".

Lo importante en este aspecto es verificar cómo algunos estudiantes, teniendo en cuenta los conceptos trabajados con el documental, lograron no sólo alcanzar la representación saturada, sino también la figura que trasciende lo textual y llega a ser significado en su relación con el mundo: "los hombres (los protagonistas) son de izquier$\mathrm{da}$, profe, porque se ve que ellos tienen ideales y luchan contra el Gobierno; deben ser guerrilleros". Este tipo de producciones textuales dejaron ver cómo la intertextualidad sí potencia la comprensión e interpretación. Además, en los casos en los que apareció esa lectura sobre imágenes de representación se pueden apreciar indicios de configuración del efecto estético, que evidenciaron las síntesis pasivas, dejando la actitud moralista vista en tantos estudiantes con respecto a la película, y permitieron la elaboración de la figura de sentido y significado sobre el proceso político y de violencia del país.

\section{Módulo 2. Sexo, drogas y literatura}

Durante la proyección de la película La mala educación de Almodóvar, hubo expresiones de rechazo por la conducta sexual de los protagonistas de la historia, pero esto no hizo que dejaran de prestar atención, dado el aporte de "herramientas conceptuales" y la vinculación de las temáticas de los textos con los contextos propios de los lectores.

Si bien se dieron escasas imágenes de representación, las de percepción se constituyeron en el insumo para interactuar con los poemas de Gómez Jattin, pues antes que expresar opiniones acerca de su sentido o significado, los estudiantes se refirieron a las imágenes que el texto suscitaba en ellos. Una afirmación que sustenta lo anterior y evidencia el distanciamiento de los estudiantes 
de los juicios morales en pro del goce estético, es la siguiente: "es chévere saber cómo dos hombres tienen sexo, sin que sea de una manera vulgar, porque en ellos también hay ternura".

Cuando la estudiante que hizo esta afirmación habla de "saber cómo" es el coito de dos hombres, se infiere que ha sucedido "algo" en ella que la ha llevado a representar esa situación, reconociendo la intención del poeta en cuanto identifica la ternura del acto y se libera de prejuicios morales, de modo que evidencia horizontes de sentido del poema, sumados a su repertorio o banco de imágenes. Igualmente, los estudiantes imaginaron que el erotismo de los poemas era de carácter heterosexual cuando sólo habían leído el título y unos cuantos versos; situación que cambió rápidamente al encontrar imágenes y metáforas que activaron sus imágenes de representación: la "colisión de espadas" o "mi caverna de Platón carnal y gnóstica/ por donde te escapas a la otra vida", del poema "El disparo final en la Vía Láctea".

En cuanto a Elogio de los alucinógenos, establecieron la asociación de los males que la "cannabis sativa" produjo en el poeta, con el amor por una persona u otros aspectos de su experiencia vital, de modo que los horizontes de sentido del poema se ampliaron hacia su mundo. Por lo anterior, es posible afirmar que en esta etapa, y con los escasos recursos extraliterarios que se habían brindado, los estudiantes entreveían un camino para llegar al efecto estético.

\section{Módulo 3. Amor y literatura}

Desde que los estudiantes comenzaron a ver la película Corre, Lola, corre se evidenció la extrañeza ante su formato cinematográfico, lo cual se manifestó en las producciones textuales sobre la experiencia con la película, la mayoría de estudiantes coincidió en que fue muy extraña inicialmente y que durante su transcurso la pudieron entender mejor. "No sabía qué eran las fotos que pasaban en algunos personajes, pero luego se entendía que era que mostraban lo que les pasaba" o "sólo supe que no se moría en la última parte de la película", son repuestas ilustrativas las expectativas creadas, que, en su mayoría, consolidaron representaciones saturadas durante la película.

Además, se presentaron ciertas actitudes que dieron cuenta del desarrollo de síntesis pasivas, como las carcajadas en la parte en dónde la protagonista roba el banco de su padre y la policía la protege, a pesar de que el horizonte de sentido indicaba que la iban a capturar; o cuando dos personajes secundarios que se muestran como personas sumamente serias, se ven envueltos en situaciones amorosas de masoquismo.

En las producciones textuales de los estudiantes fueron recurrentes los temas del amor entre Manni y Lola, el valor del tiempo y la esclavitud humana ante su transcurrir, y lo que un estudiante denominó como "lo frágil que es la vida, que depende de cosas mínimas". Esta recurrencia demostró la existencia de diversas decisiones selectivas hechas por los estudiantes en sus procesos de lectura y una apropiación del sentido de la película.

Las imágenes descritas por los estudiantes durante la película fueron de percepción, en oposición a todos los vacíos visuales que deja una obra literaria, pues la experiencia con Fábula del mar en los ojos de Aguilera Garramuño, evidenció imágenes de representación en la interacción lector-texto. Tres aspectos de la minificción demostraron contundentemente este hecho: las alusiones al mar, a la desnudez y a la expresión "pájaros en la cabeza". Muchos estudiantes dijeron sentir "el impacto de conocer el mar, aunque yo personalmente no lo conozco" o "saber que el mar es inmenso, que es grande y que como el amor no se puede agarrar" y, en el caso de la desnudez, dijeron "ver a esa mujer llena de confianza" o "la desnudez es lo más íntimo, una mujer no lo hace porque sí", entre otras respuestas que indicaban un mayor nivel de interpretación al mostrado en los módulos anteriores.

Sin embargo, la expresión "pájaros en la cabeza" dio cuenta de los avances más importantes en imágenes de representación. Como: "yo imaginé una estatua de la mujer sobre la que se paran los pájaros", "los pájaros son de lejos del suelo como los pensamientos de un loco", "los pájaros no tienen la cabeza quieta" o "la mujer está loca de amor". Del mismo modo, algunas aclaraciones sobre la obra del autor y el establecimiento por parte de los estudiantes de una verdadera relación de intertextualidad entre la película y el cuento (la manera distinta de mostrar una relación amorosa, el estado de vértigo y locura por amor, o la prueba de los protagonistas para consolidar su relación) recalcaron el avance en términos de sentido y significado, que no había aparecido en la proyección del filme, evidenciando la formación de figuras, síntesis pasivas y, por tanto, del efecto estético. 


\section{Conclusiones}

Diversas tensiones se desarrollan en la enseñanza de la lectura literaria: el profesor media entre el estudiante y el texto, pero tal mediación puede basarse en la creación de espacios de lectura y acercamiento a saberes que potencien la comprensión e interpretación textuales, o a la emisión de prejuicios morales, sociales o historiográficos indiscutibles que limiten los horizontes de sentido de la obra.

Así mismo, la normatividad vigente pretende ser innovadora en relación con el efecto estético y el placer por la lectura, tendientes a la consolidación lectora, en oposición a la pervivencia, en la práctica, de métodos tradicionales que hacen de la clase de literatura, no el espacio de lectura de obras literarias, sino un dispositivo de repetición axiomática de ciertos elementos de la historia de la literatura. Es más, resulta contradictorio que el mismo sistema educativo que propende por una libertad lectora que posibilite el goce estético, establezca unos modelos mínimos de calidad referidos a pruebas estandarizadas, sin respetar los gustos, tiempos de interacción con el texto y conocimientos de los lectores en formación.

Frente a esta situación, resulta pertinente un proceso de lectura que involucre la experiencia vital y la intertextualidad, en cuanto al contexto y otros saberes que posibilitan el alcance del efecto estético, aprovechando los horizontes semánticos y estéticos de la obra, y consolidando una formación lectora significativa para interactuar con cualquier tipo de texto.

El lenguaje cinematográfico es pertinente para este propósito, pero es necesario diferenciarlo muy bien del literario, pues la literatura exige la producción de imágenes de representación, mientras que el carácter audiovisual del cine presenta las imágenes de manera explícita, limitando lo sugerido; más aún para jóvenes habitantes de un universo iconográfico. Sin embargo, esto no constituye una desventaja para los estudiantes lectores, pues con estas imágenes se crea un repertorio en sus mentes, que les permitirá asociarlas con los contenidos literarios, creando imágenes nuevas, producto de su representación.

Por lo demás, la comprensión de la literatura como experiencia e indagación por la condición humana, no implica que todos los seres humanos tengan la obligación de experimentarla, ni siquiera de sospe- charla, pues los que la amamos tampoco tenemos que entender qué sucede cuando los campos gravitatorios de dos agujeros negros se aproximan, así esto amenace la extinción del planeta, y con él, de los libros. Por ello, esta propuesta es sólo una invitación a dejarse inocular por esa revelación que siempre ha estado esperando nuestra llamada: la literatura.

\section{Referencias}

Borges, J. (2001). Arte poética. Barcelona: Crítica.

Bruner, J. (2004). Realidad mental y mundos posibles. Los actos de la imaginación que dan sentido a la experiencia. Barcelona: Gedisa.

Colomer, T. (1995).La adquisición de la competencia literaria. En: Lomas, C. (Comp.). La educación literaria. Textos de Didáctica de la lengua y de la literatura. No. 4, Año II. Barcelona: Graó.

Ferreiro, E. (2001). Pasado y presente de los verbos leer y escribir. México: FCE.

Ferrer, E. (2002). Literatura y teoría literaria: el ser como construcción simbólica. Papeles. Bogotá: UAN, 16.

Fortich, M. (2008, Enero-Junio). Sensibilidad literaria: apuntes para una reflexión sobre una didáctica. Itinerario educativo. No. 51. Año XXII.

Freire, P. (2005). La importancia de leer y el proceso de liberación. México: Siglo XXI.

Gimferrer, P. (2000). Cine y literatura. Barcelona: Seix Barral.

Iser, W. (1987). El acto de leer. Teoría del efecto estético. Madrid: Taurus.

Lerner, D. (2001). Leer y escribir en la escuela: lo real, lo posible y lo necesario. México: FCE.

Larrosa, J. (1998). La experiencia de la lectura. Estudios sobre literatura y formación. Barcelona: Laertes.

Mckernan, J. (2001). Investigación-acción y currículo. Madrid: Morata.

Martínez, J. (2001). La intertextualidad literaria. Baseteórica y práctica textual. Madrid: Cátedra, 45, 74.

MEN. (1998). Lineamientos curriculares de Lengua Castellana. Bogotá: MEN.

MEN. (2003). Estándares de Lenguaje. Lengua castellana, literatura y otros sistemas simbólicos. Bogotá: MEN, 23.

Reyzábal, M., y Tenorio, P. (1994). El aprendizaje significativo de la literatura. Madrid: La Muralla, 38.

Ricoeur, P. (1995). Tiempo y narración. México: Siglo XXI.

Pujals, G. y Romea, C. (2001). Cine y literatura. Relación y posibilidades didácticas. Barcelona: I.C.E.

Venegas, M. (2001). Módulo sobre hábitos de lectura y consumo de libros: una mirada desde la escuela. En: Rey, G. (2001). Hábitos de lectura y consumo de libros en Colombia. Bogotá: Fundalectura.

Zabala, L. (2005). La minificción bajo el microscopio. Bogotá: UPN. 


\section{Diálogo del conocimiento}

La investigación-acción, esbozada en este artículo, está encaminada a avivar el proceso de lectura particular del colectivo intervenido, propiciando un efecto estético como estrategia para ampliar los horizontes de sentido y mejorar la interpretación textual. Los actores educativos son los profesores y estudiantes, la problemática a abordar es la lectura de textos literarios y la hipótesis de trabajo planteada, es que el logro del efecto estético en la interacción lectura-textos contribuye a la formación de los estudiantes en las áreas de lenguaje y literatura.

La propuesta se aborda desde cuatro aspectos teóricos. Primero, la didáctica de la literatura para la vida con el fin de crear un contexto que vincule autor, obra y lector. Segundo, la lectura como experiencia estética, distinguiendo la creación de la obra (autor/polo artístico) y la experiencia -única, personal e irrepetible- de concreción del texto (lector/ polo estético). Tercero, los fundamentos fenomenológicos del proceso de lectura, que incluyen: la noción de punto móvil, referida a la disponibilidad de la totalidad del texto en diferentes momentos de la lectura, a través de un proceso que conjuga recuerdos y expectativas (síntesis). Y cuarto, la noción de intertextualidad que alude a la relación interna de un texto con otros textos, sean o no literarios.

El trabajo consta de dos ciclos, uno de diagnóstico y exploración para conocer la situación inicial del colectivo a intervenir, cuyo resultado muestra, según los autores, la falta de relación entre las obras literarias y las vidas de los lectores. En el ciclo de aplicación, se recurre al uso de extratextos para dar el contexto de la obra, de los intratextos para conocer los modos de narración del grupo analizado y del cine y la minificción, que por sus rasgos de brevedad y contundencia resultan cercanos al mundo juvenil. Se desarrolla en tres etapas, en cada una de las cuales se presenta un filme, se realiza un conversatorio y se elabora un escrito, para lo cual se proponen textos relacionados con las temáticas trabajadas, de modo que apoyen la interpretación de las películas.

En este sentido, la idea de la literatura como experiencia que indaga por la condición humana, que exige la producción de imágenes de representación, plantea un horizonte de trabajo rico e interesante tanto para maestros como para estudiantes, en la medida que señala un camino a explorar para trabajar la lectoescritura en el aula. Además, la vinculación de la lectura con la escritura constituye un acierto de la propuesta, por cuanto son procesos conexos que implican conocer la organización de los textos; asunto central para realizar la inscripción y su interpretación de forma significativa, en tanto las imágenes evocadas y la experiencias percibidas no son patrimonio exclusivo del lector, ni están sólo en el texto, sino que se despliegan en la interacción entre el texto y el lector.

Si bien la etapa de diagnóstico no aporta elementos distintos a los ya conocidos -falta de interés, pobreza de referentes y uso instrumental de los textos y de la lectura, entre otros- que hacen de esta una actividad poco o nada significativa, sin lugar a dudas, la hipótesis del trabajo resulta inspiradora y absolutamente pertinente. Pues aunque no existen vías de solución definitivas contra la apatía y la pobreza de referentes intelectuales, materiales y espirituales, la estrategia de involucrar la experiencia vital del lector y configurar un contexto a partir de la movilización de otros saberes resulta relevante para generar un ambiente más propicio para hacer de la lectura una experiencia plena, íntimamente ligada a la existencia.

Así, el valor de la propuesta radica no en su novedad, sino en la apuesta que se hace de desarrollar el gusto por la lectura a través del cultivo de la experiencia estética. Ya que reivindica la idea de que solo se ama aquello que se conoce y solo se aprende a plenitud aquello que se disfruta. Señalando una ruta para abordar la lectura en el aula y generar mayor la disposición para realizarla. 